This is a post-peer-review, pre-copyedit version of an article published in 'Drug Safety'. The final authenticated version is available online at: https://doi.org/10.1007/s40264-019-00842-1. The following terms of use apply: https://www.springer.com/gp/ope

\title{
Comparative effectiveness and safety of direct oral anticoagulants in patients with atrial fibrillation: A systematic review and meta-analysis of observational studies
}

\section{Running Head: DOACs in AF}

Authors: Antonios Douros MD PhD ${ }^{1,2,3}$, Madeleine Durand MD MSc ${ }^{4}$, Carla M. Doyle MSc ${ }^{1,2}$, Sarah Yoon BSc ${ }^{1,2}$, Pauline Reynier MSc${ }^{1}$, Kristian B. Filion $\mathrm{PhD}^{1,2,5}$

\section{Author affiliations:}

1. Centre for Clinical Epidemiology, Lady Davis Institute for Medical Research, Jewish General Hospital, Montréal, Quebec, Canada

2. Department of Epidemiology, Biostatistics, and Occupational Health, McGill University, Montreal, Quebec, Canada

3. Institute of Clinical Pharmacology and Toxicology, Charité - Universitätsmedizin Berlin, corporate member of Freie Universität Berlin, Humboldt-Universität zu Berlin, and Berlin Institute of Health, Berlin, Germany

4. Department of Internal Medicine, Centre Hospitalier de l'Université de Montréal, Montreal, Quebec Canada

5. Department of Medicine, McGill University, Montreal, Quebec, Canada

\section{Word Count Main Text: 4350}

Tables: 2; Figures: 2; Online Appendices: 24

Keywords: non-vitamin $\mathrm{K}$ antagonist oral anticoagulants, ischemic stroke, major bleeding, systematic review, meta-analysis

\section{Address for Correspondence:}

Kristian B. Filion, $\mathrm{PhD}$

Assistant Professor and William Dawson Scholar, Departments of Medicine and of Epidemiology, Biostatistics, and Occupational Health, McGill University

Centre for Clinical Epidemiology, Lady Davis Research Institute, Jewish General Hospital 3755 Cote Ste-Catherine, Suite H410.1

Montreal, Quebec H3T 1E2 Canada

Tel.: (514) 340-8222 ext 28394

Fax: (514) 340-7564

Email: kristian.filion@mcgill.ca

Prior posting and presentation: This work is the sole product of the authors and has never been submitted for publication or presented in a public setting. 
This is a post-peer-review, pre-copyedit version of an article published in 'Drug Safety'. The final authenticated version is available online at: https://doi.org/10.1007/s40264-019-00842-1. The following terms of use apply: https://www.springer.com/gp/ope

\section{ABSTRACT}

Background: There are no head-to-head randomized controlled trials comparing different direct oral anticoagulants (DOACs). Thus, we systematically reviewed and meta-analyzed observational studies assessing the comparative effectiveness and safety of DOACs for stroke prevention in patients with atrial fibrillation (AF).

Methods: We systematically searched MEDLINE and EMBASE up to February 2019 for observational studies comparing head-to-head different DOACs in patients with AF. Two independent reviewers identified studies, extracted data, and assessed the risk of bias using the ROBINS-I tool. Random-effects models were used to meta-analyze data across higher quality studies.

Results: We identified 25 cohort studies including 1,079,565 patients with AF treated with DOACs. Meta-analysis of the 19 studies at moderate risk of bias yielded a similar risk of ischemic stroke for rivaroxaban versus dabigatran (6 studies; hazard ratio [HR], 0.93; 95\% confidence interval $[\mathrm{CI}], 0.83$ to $1.04 ; \mathrm{I}^{2}: 0 \%$ ), for apixaban versus dabigatran (5 studies; HR, 0.94; 95\% CI, 0.82 to $1.09 ; \mathrm{I}^{2}: 0 \%$ ), and for apixaban versus rivaroxaban (4 studies; HR, $1.07 ; 95 \% \mathrm{CI}, 0.93$ to $\left.1.23 ; \mathrm{I}^{2}: 0 \%\right)$. Regarding major bleeding, there was an increased risk for rivaroxaban versus dabigatran (6 studies; HR, 1.33; 95\% CI, 1.20 to 1.47; $\mathrm{I}^{2}: 22 \%$ ) and decreased risks for apixaban versus either dabigatran ( 8 studies; HR, $0.71 ; 95 \% \mathrm{CI}, 0.64$ to $\left.0.78 ; \mathrm{I}^{2}: 0 \%\right)$ or rivaroxaban $(8$ studies; HR, 0.56 ; $95 \% \mathrm{CI}, 0.48$ to $0.65 ; \mathrm{I}^{2}: 69 \%$ ).

Conclusions: As head-to-head trials comparing different DOACs do not exist, available evidence derives exclusively from observational studies. These data suggest that while dabigatran, rivaroxaban, and apixaban have a similar effect on the risk of ischemic stroke, apixaban may be associated with a decreased risk of major bleeding compared with either dabigatran or rivaroxaban. 
This is a post-peer-review, pre-copyedit version of an article published in 'Drug Safety'. The final authenticated version is available online at: https://doi.org/10.1007/s40264-019-00842-1. The following terms of use apply: https://www.springer.com/gp/ope

\section{KEY POINTS}

- Dabigatran, rivaroxaban, and apixaban are associated with similar risks of ischemic stroke in patients with atrial fibrillation.

- Rivaroxaban is associated with an increased risk of major bleeding compared with dabigatran in patients with atrial fibrillation.

- Apixaban is associated with a decreased risk of major bleeding compared with either dabigatran or rivaroxaban in patients with atrial fibrillation. 
This is a post-peer-review, pre-copyedit version of an article published in 'Drug Safety'. The final authenticated version is available online at: https://doi.org/10.1007/s40264-019-00842-1. The following terms of use apply: https://www.springer.com/gp/ope

\section{INTRODUCTION}

Atrial fibrillation (AF) is a common cardiac arrhythmia that increases the risk of ischemic stroke five-fold.[1] While vitamin $\mathrm{K}$ antagonists (VKAs) have long been the primary oral anticoagulants for stroke prevention in AF, they are prone to drug-drug interactions and need frequent monitoring.[2] Direct oral anticoagulants (DOACs), including the thrombin inhibitor dabigatran and the Factor Xa inhibitors rivaroxaban, apixaban, and edoxaban, expanded recently our pharmacologic arsenal. They were found to be either non-inferior or superior to the VKA warfarin for stroke prevention in large randomized controlled trials and have several advantages over VKAs, including more rapid onset of anticoagulation and decreased need for monitoring.[3] Consequently, treatment guidelines now recommend DOACs as first-line oral anticoagulation among patients with AF.[4-6]

To date, there are no large, head-to-head trials comparing different DOACs in patients with AF. Moreover, there is a need to assess the comparative effectiveness and safety of DOACs in real-world settings. While four publications to date have systematically reviewed and metaanalyzed available real-world data,[7-10] one used outdated tools for the assessment of the risk of bias,[7] while others omitted bias assessment altogether.[8, 9] Moreover, numerous studies reporting head-to-head comparisons among DOACs that were recently published were not included in these earlier works.[11-27]

Thus, the objective of this systematic review and meta-analysis of observational studies was to provide an up-to-date synthesis of the available real-world evidence on DOAC comparative effectiveness and safety in patients with AF, while thoroughly assessing the risk of bias of the included studies. 
This is a post-peer-review, pre-copyedit version of an article published in 'Drug Safety'. The final authenticated version is available online at: https://doi.org/10.1007/s40264-019-00842-1. The following terms of use apply: https://www.springer.com/gp/ope

\section{METHODS}

This systematic review and meta-analysis was conducted according to a pre-specified protocol and is reported following the Preferred Reporting Items for Systematic Reviews and Meta-Analyses [28] and Meta-Analysis of Observational Studies in Epidemiology.[29]

\subsection{Search strategy}

MEDLINE and EMBASE were systematically searched from inception to February 28, 2019 for observational studies published in English in the peer-reviewed literature and comparing DOACs to each other in patients with AF. The search strategy was tailored to each database and included index terms (MeSH and Emtree) and text words related to AF and DOACs (see Electronic Supplementary Material eTable 1). We also scanned the bibliographies of the included articles and relevant reviews for further references.

\subsection{Inclusion and exclusion criteria}

Randomized controlled trials, cross-sectional studies, letters to the editor, commentaries/editorials, and previous reviews and meta-analyses were excluded. Conference abstracts were also excluded, as their results are often preliminary, and they contain insufficient information to adequately assess risk of bias. To minimize the potential effects of publication bias, we excluded studies with less than 1000 DOAC users. Studies looking at DOAC use in AF patients undergoing ablation were also excluded, as their results are not generalizable to AF patients in general.

Studies eligible for inclusion were cohort or case-control studies comparing DOACs (apixaban, dabigatran, rivaroxaban, or edoxaban) to each other in patients with AF. The primary 
This is a post-peer-review, pre-copyedit version of an article published in 'Drug Safety'. The final authenticated version is available online at: https://doi.org/10.1007/s40264-019-00842-1. The following terms of use apply: https://www.springer.com/gp/ope

effectiveness outcome was ischemic stroke, while the primary safety outcome was major bleeding. Secondary effectiveness outcomes were all-cause mortality, myocardial infarction, and systemic embolism. Secondary safety outcomes included intracranial hemorrhage, hemorrhagic stroke, gastrointestinal bleeding, and other bleeding events.

\subsection{Study selection}

Two independent reviewers (either CMD/SY or AD/SY) performed study selection. Titles and abstracts were screened to identify potentially relevant studies and duplicates; all studies identified as potentially relevant by either reviewer proceeded to full-text review. Full-text review established the final set of included studies, with discrepancies resolved by consensus.

\subsection{Data extraction}

Two independent reviewers (either CMD/SY or AD/SY) extracted data using a pilot-tested form, with discrepancies resolved by consensus (see Electronic Supplementary Material eTable 2). Study characteristics included study design, location, data source, study period, sample size (overall and by exposure group), follow-up duration, patient characteristics (age, sex, $\mathrm{CHADS}_{2}$ [congestive heart failure, hypertension, age $\geq 75$ years, diabetes mellitus, prior stroke or transient ischemic attack] score[30] or $\mathrm{CHA}_{2} \mathrm{DS}_{2}$-VASc [congestive heart failure, hypertension, age $\geq 75$ years, diabetes mellitus, prior stroke or transient ischemic attack, vascular disease, age 65-74 years, female sex] score[31] or their components, and HAS-BLED [hypertension, abnormal renal/liver function, prior stroke, bleeding history or predisposition, labile international normalized ratio, age >65 years, drugs] score[32] and its components), and study outcomes. Other items extracted to describe the methodological approach and assess risk of bias included use of a new-user design, 
This is a post-peer-review, pre-copyedit version of an article published in 'Drug Safety'. The final authenticated version is available online at: https://doi.org/10.1007/s40264-019-00842-1. The following terms of use apply: https://www.springer.com/gp/ope

exposure definition (e.g., intention-to-treat, as-treated, time-dependent, etc.), and handling of treatment switch or discontinuation. The main summary measures of interest were hazard ratios (HR) or odds ratios (OR) with $95 \%$ confidence intervals (CIs). Effect estimates were presented for the comparisons rivaroxaban versus dabigatran, apixaban versus dabigatran, and apixaban versus rivaroxaban. For articles reporting effect estimates with a different DOAC as comparator (e.g., dabigatran versus rivaroxaban), comparator was changed, and reciprocal results were calculated.

\subsection{Assessment of risk of bias}

Two independent reviewers (AD/SY) assessed the risk of bias using the Risk Of Bias In Non-randomized Studies of Interventions (ROBINS-I) tool.[33] Seven domains were assessed: bias due to confounding; bias in the selection of study participants; bias in the classification of interventions; bias due to departure from intended interventions; bias due to missing data; bias in the measurement of outcomes; and bias in the selection of the reported results. Based on the assessment of each domain, an overall risk of bias was assigned as low, moderate, serious, or critical, with the overall risk determined by the highest risk assigned in any individual domain.[33] Given the potential for confounding inherent in observational studies, the highest quality studies were those with an overall moderate risk of bias. A moderate risk of confounding bias was ascribed to studies considering at least the following covariates in their design or analysis: age, sex, prior use of warfarin, use of antiplatelets, previous stroke (for stroke outcomes), $\mathrm{CHADS}_{2}$ or $\mathrm{CHA}_{2} \mathrm{DS}_{2-}$ VASC score or their components (for stroke outcomes), previous bleeding (for bleeding outcomes), and HAS-BLED score or its components (for bleeding outcomes). 
This is a post-peer-review, pre-copyedit version of an article published in 'Drug Safety'. The final authenticated version is available online at: https://doi.org/10.1007/s40264-019-00842-1. The following terms of use apply: https://www.springer.com/gp/ope

\subsection{Data analysis}

Data were pooled across studies using DerSimonian and Laird random-effects models with Mantel-Haenszel weighting for each outcome reported by at least three studies at moderate risk of bias. Meta-analytic results are presented as pooled adjusted HRs with 95\% CIs. The amount of heterogeneity that was present was estimated using the $\mathrm{I}^{2}$ statistic. All analyses were conducted using $\mathrm{R}$ version 3.2.2.

During the literature search, we observed that some studies used the same data sources. Thus, to avoid the duplicate inclusion of participants in the meta-analysis, we decided that, in cases of chronologically overlapping studies using the same data sources and assessing the same outcome, only the most recent one would be included. Moreover, given that one study combined five different data sources resulting in overlaps with several other studies, we decided to exclude it from the meta-analysis.[25] However, the results of this study for the two primary outcomes were included in sensitivity analyses where the overlapping studies were excluded instead. 
This is a post-peer-review, pre-copyedit version of an article published in 'Drug Safety'. The final authenticated version is available online at: https://doi.org/10.1007/s40264-019-00842-1. The following terms of use apply: https://www.springer.com/gp/ope

\section{RESULTS}

\subsection{Search results}

The search performed yielded 9512 studies, of which 9316 were excluded during title/abstract screening (see Electronic Supplementary Material eFigure 1). The remaining 196 studies underwent full-text review, and 25 of those were included in the systematic review.[11-27, $34-41]$

\subsection{Study characteristics}

All twenty-five included studies were cohort studies published between 2016 and 2019. They included a total of 1,079,565 patients (380,682 treated with dabigatran, 452,611 with rivaroxaban, and 246,272 with apixaban). The follow-up durations ranged from 89 to 422 days (Table 1). Overall, fifteen studies were conducted in North America,[11, 12, 16, 17, 19, 20, 23-26, 34, 36, 38, 39, 41] seven in Europe,[14, 18, 21, 22, 27, 37, 40] and 3 in Asia.[13, 15, 35] Eighteen studies compared dabigatran with rivaroxaban, $[11-13,15,17,18,21-23,25,26,34,35,37-41]$ while seventeen considered also apixaban (Table 1).[11, 12, 14, 16, 18-21, 23-27, 34, 36, 40, 41] No studies examined edoxaban. One study used two different databases and reported separate estimates for each.[36] While all twenty-five studies included patients with AF, eighteen considered patients initiating oral anticoagulation with DOACs (i.e., new users of DOACs without previous VKA use),[12, 14, 16-27, 34, 37, 38, 40] four considered new users of DOACs with previous VKA use,[11, 13, 39, 41] one considered new users of dabigatran or rivaroxaban with previous use of VKAs or other DOACs,[35] and two considered both new and prevalent users of DOACs $[15,36]$ (Table 1). In nine studies there were separate analyses for standard-dose and lowdose treatment regimes.[18-20, 22, 24, 25, 37-39] 
This is a post-peer-review, pre-copyedit version of an article published in 'Drug Safety'. The final authenticated version is available online at: https://doi.org/10.1007/s40264-019-00842-1. The following terms of use apply: https://www.springer.com/gp/ope

Patient characteristics including age, heart failure, renal disease, and previous stroke or bleeding differed across studies (see Electronic Supplementary Material eTable 3). $\mathrm{CHA}_{2} \mathrm{DS}_{2-}$ VASc scores ranged from 1.6 to 4.7, while HAS-BLED scores ranged from 1.2 to 3.7. In nineteen studies exposure was defined in an as-treated fashion, where patients were considered continuously exposed until drug discontinuation,[11-13, 16, 18-27, 34, 38-41] five studies used an intention-to-treat approach, where exposure was defined by treatment at cohort entry,[15, 17, 3537] and one used a time-dependent exposure definition (censoring follow-up upon discontinuation of oral anticoagulation) [14] in their main analyses. Five studies used alternative exposure definitions in sensitivity analyses.[20, 24, 35, 37, 41] Among the seven studies not explicitly excluding patients with previous VKA use, $[11,13,15,35,36,39,41]$ three accounted for it at the stage of statistical analysis,[11, 13, 41] while the other four did not.[15, 35, 36, 39]

\subsection{Assessment of risk of bias}

Based on ROBINS-I, nineteen studies were assigned a moderate risk of bias,[11, 12, 16-27, $34,37,38,40,41]$ four were assigned a serious risk of bias, $[13,14,35,39]$ and two were assigned a critical risk of bias [15, 36] (see Electronic Supplementary Material eTable 4). As one of the studies at moderate risk of bias reported only absolute risk differences,[18] its results are presented in the tables but not included in qualitative or quantitative data synthesis. One domain leading to a major increase in the risk of bias was 'risk of bias due to confounding', resulting from confounding by indication, contraindication and/or severity associated with previous use of VKAs,[15, 35, 36, 39] time-varying confounding due VKA use during follow-up,[14] or from residual confounding due to failure to adjust for important confounders.[13] Eighteen studies used propensity score-based approaches in their analyses to control for confounding.[11, 13, 16, 17, 19- 
This is a post-peer-review, pre-copyedit version of an article published in 'Drug Safety'. The final authenticated version is available online at: https://doi.org/10.1007/s40264-019-00842-1. The following terms of use apply: https://www.springer.com/gp/ope

$26,34,37-41]$ A propensity score is defined as the probability of getting exposed to a medication, given a set of covariates.[42]. As this score summarizes all patient characteristics into a single covariate, it reduces the potential for overfitting. However, the possibility of confounding due to unmeasured covariates cannot be excluded.

Another domain responsible for an increased risk of bias was 'bias in selection of participants into the study', resulting from the inclusion of previous users of VKAs [35, 39] or DOACs, [15, 36] as well as from potential informative censoring in the setting of an as-treated exposure definition.[11-13, 16, 18, 19, 21-23, 25-27, 34, 38-41] Of note, no study using an as-treated definition included statistical approaches to address informative censoring (e.g., inverse probability of censoring weights). However, three studies using both as-treated and intention-totreat definitions (in sensitivity analyses) while not having other sources of selection bias were ascribed a low risk in this respect given the complementary nature of these analyses.[20, 24, 37] Moreover, considering the short follow-up of the included studies ( $<1$ year) and the resulting low risk of exposure misclassification, studies using an intention-to-treat approach were ascribed a low risk of "bias in classification of interventions". Finally, 'bias in selection of reported results' due to the absence of a prespecified study protocol also affected the quality of most of the included studies (see Electronic Supplementary Material eTable 4).

\subsection{DOACs and ischemic stroke}

The results for ischemic stroke were heterogenous for all three comparisons (see Electronic Supplementary Material eTable 5). Fifteen studies compared rivaroxaban with dabigatran with HRs ranging from 0.73 to $1.92 .[12,13,15,17,18,21-23,25,26,35,37-39,41]$ Nine studies compared apixaban with dabigatran with HRs ranging from 0.40 to $1.22 .[12,18,19,21,23,25-$ 
This is a post-peer-review, pre-copyedit version of an article published in 'Drug Safety'. The final authenticated version is available online at: https://doi.org/10.1007/s40264-019-00842-1. The following terms of use apply: https://www.springer.com/gp/ope

27, 41] Finally, eight studies compared apixaban with rivaroxaban with HRs ranging from 0.67 to 1.27.[12, 18, 19, 21, 23, 25, 27, 41]

\subsection{DOACs and major bleeding}

Ten studies compared the risk of major bleeding between rivaroxaban and dabigatran showing either a trend towards an increased risk or a significantly increased risk with rivaroxaban, with HRs ranging from 1.05 to 1.69 (see Electronic Supplementary Material eTable 6).[21, 22, 25, 26, 34, 35, 39-41] Fourteen studies compared apixaban with dabigatran showing either a trend towards an decreased risk or a significantly decreased risk with apixaban (HR range: 0.50 to 0.94).[14, 16, 18-21, 24-27, 34, 36, 40, 41] Finally, thirteen studies compared apixaban with rivaroxaban, showing either a trend towards a decreased risk or a significantly decreased risk with apixaban (HR range: 0.39 to 0.88$).[14,16,18-21,24,25,27,34,36,40,41]$

\subsection{DOACs and secondary effectiveness outcomes}

Eight studies compared the risk of all-cause mortality between rivaroxaban and dabigatran, with most of them showing either a trend towards an increased risk or a significantly increased risk for rivaroxaban, with HRs ranging from 0.99 to 1.52 (see Electronic Supplementary Material eTable 7).[13, 22, 23, 26, 35, 37-39] Moreover, three studies compared apixaban with dabigatran, showing no statistically significance difference (HR range: 0.91 to 1.14).[23, 26, 27] Two studies compared apixaban with rivaroxaban, showing either a trend towards a decreased risk or a significantly decreased risk with apixaban (HR range 0.81 to 0.94$).[23,27]$

Six studies compared the risk of myocardial infarction between rivaroxaban and dabigatran, yielding heterogenous results, with HRs ranging from 0.62 to 1.11 (see Electronic 
This is a post-peer-review, pre-copyedit version of an article published in 'Drug Safety'. The final authenticated version is available online at: https://doi.org/10.1007/s40264-019-00842-1. The following terms of use apply: https://www.springer.com/gp/ope

Supplementary Material eTable 8).[13, 17, 22, 26, 35, 38] Moreover, one study compared apixaban with dabigatran, showing a strongly decreased risk with apixaban (HR, 0.37; 95\% CI, $0.16-0.84) \cdot[26]$

Five studies compared the risk of systemic embolism between rivaroxaban and dabigatran showing either a trend towards an increased risk or a significantly increased risk with rivaroxaban with HRs ranging from 1.09 to 1.47 (see Electronic Supplementary Material eTable 9).[13, 21, $22,25,39]$. Two studies compared apixaban with dabigatran, showing a trend towards a decreased risk with apixaban (HR range: 0.37 to 0.76$),[19,25]$. Three studies compared apixaban with rivaroxaban, also showing a trend towards a decreased risk with apixaban (HR range: 0.49 to 0.56).[19, 21, 25])

\subsection{DOACs and secondary safety outcomes}

The results for intracranial hemorrhage were heterogenous for all three comparisons (see Electronic Supplementary Material eTable 10). Fourteen studies compared rivaroxaban with dabigatran with HRs ranging from 0.73 to $3.45 .[12,13,17,18,21-23,25,26,34,35,38,39$, 41] Ten studies compared apixaban with dabigatran with HRs ranging from 0.65 to 1.43.[12, 18, 19, 21, 23, 25-27, 34, 41] Finally, nine studies compared apixaban with rivaroxaban with HRs ranging from 0.51 to $1.39 .[12,18,19,21,23,25,27,34,41]$

Four studies comparing the risk of hemorrhagic stroke between rivaroxaban and dabigatran, showing either a trend towards an increased risk or a significantly increased risk with rivaroxaban, with HRs ranging from 1.70 to 4.55 (see Electronic Supplementary Material eTable 11).[21, 25, 26, 41] Four studies compared apixaban with dabigatran, showing no statistically significant 
This is a post-peer-review, pre-copyedit version of an article published in 'Drug Safety'. The final authenticated version is available online at: https://doi.org/10.1007/s40264-019-00842-1. The following terms of use apply: https://www.springer.com/gp/ope

difference (HR range: 0.72 to 1.08).[19, 21, 25, 41] Finally, four studies compared apixaban with rivaroxaban, yielding heterogenous results with HRs ranging from 0.32 to 1.49.[19, 21, 25, 41]

Fourteen studies compared the risk of gastrointestinal bleeding between rivaroxaban and dabigatran (see Electronic Supplementary Material eTable 12).[11-13, 17, 18, 21-23, 25, 26, 34, 35, 38, 39] Except for one study showing a trend towards a decreased risk with rivaroxaban (HR, 0.85; 95\% CI, 0.72 to 1.01),[34] the other studies showed either a trend towards an increased risk or a significantly increased risk with rivaroxaban, with HRs ranging from 1.12 to 1.60.[11-13, $17,18,21-23,25,26,35,38,39]$ Ten studies compared apixaban with dabigatran, showing either a trend towards a decreased risk or a significantly decreased risk with apixaban (HR range: 0.39 to 0.86$).[11,12,18,19,21,23,25-27,34]$ Finally, nine studies compared with apixaban with rivaroxaban, showing either a trend towards a decreased risk of a significantly decreased risk with apixaban (HR range: 0.33 to 0.94).[11, 12, 18, 19, 21, 23, 25, 27, 34]

Several studies assessed the risk of further bleeding outcomes including any bleeding[12, 37, 39], major extracranial bleeding, [23, 26, 38] hospitalized extracranial bleeding,[38] clinically relevant bleeding,[22] and urogenital bleeding.[22, 27] The results are shown in Electronic

\section{Supplementary Material eTable 13.}

The results on DOAC comparative effectiveness and safety did not considerably change when comparing low-dose regimes (see Electronic Supplementary Material eTable 14) or using alternative exposure definitions (see Electronic Supplementary Material eTable 15).

\subsection{DOAC effectiveness and safety in higher quality studies}

When considering only the nineteen studies at moderate risk of bias and only outcomes assessed by more than one study, qualitative data synthesis remained inconclusive regarding the 
This is a post-peer-review, pre-copyedit version of an article published in 'Drug Safety'. The final authenticated version is available online at: https://doi.org/10.1007/s40264-019-00842-1. The following terms of use apply: https://www.springer.com/gp/ope

risk of ischemic stroke (HR range for rivaroxaban versus dabigatran: 0.73 to 1.12 ; HR range for apixaban versus dabigatran: 0.40 to 1.22 ; HR range for apixaban versus rivaroxaban: 0.67 to 1.27 ). Data suggested an increased risk of major bleeding for rivaroxaban versus dabigatran (HR range: 1.05 to 1.69 ), and decreased risks for apixaban versus either dabigatran (HR range: 0.50 to 0.94 ) or rivaroxaban (HR range: 0.39 to 0.88 ).

Regarding all-cause mortality, we found a trend towards an increased risk for rivaroxaban versus dabigatran (HR range: 0.99 to 1.52 ), a similar risk for apixaban versus dabigatran (range: HR 0.91 to 1.14), and a trend towards a decreased risk for apixaban versus rivaroxaban (HR range: 0.81 to 0.94$)$. There was also a similar risk of myocardial infarction for rivaroxaban versus dabigatran (HR range: 0.88 to 1.11). Moreover, data suggested an increased risk of systemic embolism for rivaroxaban versus dabigatran (HR range: 1.09 to 1.39), and a trend towards decreased risks for apixaban versus either dabigatran (HR range: 0.37 to 0.76 ) or rivaroxaban (HR range: 0.49 to 0.56 ), albeit all studies had wide $95 \%$ CIs.

Regarding intracranial hemorrhage, data suggested an increased risk for rivaroxaban versus dabigatran (HR range: 1.05 to 1.81 ), but data on apixaban were heterogenous (HR range versus dabigatran: 0.65 to 1.75 ; HR range versus rivaroxaban: 0.51 to 1.39 ). There was also a trend towards an increased risk of hemorrhagic stroke for rivaroxaban versus dabigatran (HR range: 1.70 to 4.55), a similar risk for apixaban versus dabigatran (HR range: 0.72 to 1.08 ), and heterogenous results for apixaban versus rivaroxaban (HR range: 0.32 to 1.49). Finally, regarding gastrointestinal bleeding, the results were heterogeneous for rivaroxaban versus dabigatran (HR range: 0.85 to 1.52 ) but suggested decreased risks for apixaban versus either dabigatran (HR range: 0.39 to 0.86 ) or rivaroxaban (HR range: 0.33 to 0.94 ). 
This is a post-peer-review, pre-copyedit version of an article published in 'Drug Safety'. The final authenticated version is available online at: https://doi.org/10.1007/s40264-019-00842-1. The following terms of use apply: https://www.springer.com/gp/ope

\subsection{Meta-analysis of higher quality studies}

There was a similar risk of ischemic stroke for rivaroxaban versus dabigatran (6 studies; HR, 0.93; $95 \%$ CI, 0.83 to $1.04 ; \mathrm{I}^{2}$ : 0\%), for apixaban versus dabigatran (5 studies; HR, 0.94; 95\% CI, 0.82 to $1.09 ; \mathrm{I}^{2}: 0 \%$, and for apixaban versus rivaroxaban (4 studies; HR, $1.07 ; 95 \% \mathrm{CI}, 0.93$ to 1.23; $\mathrm{I}^{2}:$ 0\%) (Table 2, Figure 1). Regarding major bleeding, there was an increased risk for rivaroxaban versus dabigatran (6 studies; HR, 1.33; 95\% CI, 1.20 to $1.47 ; \mathrm{I}^{2}: 22 \%$ ) and decreased risks for apixaban versus either dabigatran (8 studies; HR, 0.71; 95\% CI, 0.64 to $0.78 ; \mathrm{I}^{2}$ : 0\%) or rivaroxaban (8 studies; HR, 0.56; 95\% CI, 0.48 to $0.65 ; \mathrm{I}^{2}: 69 \%$ ) (Table 2, Figure 2).

There was a borderline increased risk of all-cause mortality for rivaroxaban versus dabigatran (4 studies; HR, 1.13; 95\% CI, 1.00 to $1.28 ; \mathrm{I}^{2}: 38 \%$ ) and a similar risk for apixaban versus dabigatran (3 studies; HR, 1.00; $95 \%$ CI, 0.85 to $1.19 ; \mathrm{I}^{2}$ : 60\%) (Table 2, see also Electronic Supplementary Material eFigure 2). There was also a similar risk of myocardial infarction for rivaroxaban versus dabigatran (4 studies; HR, 0.98; 95\% CI, 0.86 to 1.12; I²: 0\%) (Table 2, see also Electronic Supplementary Material eFigure 3) and a similar risk of systemic embolism for the same comparison (3 studies; HR, 1.19; 95\% CI, 0.77 to $1.82 ; \mathrm{I}^{2}: 0 \%$ ) (Table 2, see also Electronic Supplementary Material eFigure 4).

Regarding intracranial hemorrhage, there was an increased risk for rivaroxaban versus dabigatran (7 studies; HR, 1.71; 95\% CI, 1.46 to $\left.2.01 ; \mathrm{I}^{2}: 0 \%\right)$ but a similar risk for apixaban versus either dabigatran (6 studies; HR, 1.27; 95\% CI, 0.98 to $1.63 ; \mathrm{I}^{2}: 10 \%$ ) or rivaroxaban (5 studies; HR, 0.80; $95 \%$ CI, 0.59 to 1.08; I ${ }^{2}: 37 \%$ ) (Table 2, see also Electronic Supplementary Material eFigure 5). The studies assessing hemorrhagic stroke observed similar estimates (Table 2, see also Electronic Supplementary Material eFigure 6). Regarding gastrointestinal bleeding, there was an increased risk for rivaroxaban versus dabigatran (7 studies; HR, 1.17; 95\% CI, 1.02 to 1.33; 
This is a post-peer-review, pre-copyedit version of an article published in 'Drug Safety'. The final authenticated version is available online at: https://doi.org/10.1007/s40264-019-00842-1. The following terms of use apply: https://www.springer.com/gp/ope

$\left.\mathrm{I}^{2}: 69 \%\right)$ and decreased risks for apixaban versus either dabigatran (6 studies; HR, 0.59; 95\% CI, 0.46 to $0.75 ; \mathrm{I}^{2}: 72 \%$ ) or rivaroxaban (5 studies; HR, $0.56 ; 95 \%$ CI, 0.36 to $0.86 ; \mathrm{I}^{2}: 92 \%$ ) (Table 2, see also Electronic Supplementary Material eFigure 7). Finally, the results for the two primary outcomes did not change when including the study by Lip et al.[25] (see Electronic Supplementary Material eFigures 8, 9). 
This is a post-peer-review, pre-copyedit version of an article published in 'Drug Safety'. The final authenticated version is available online at: https://doi.org/10.1007/s40264-019-00842-1. The following terms of use apply: https://www.springer.com/gp/ope

\section{DISCUSSION}

The objective of our study was to synthesize the available real-world evidence on the comparative effectiveness and safety of DOACs. Overall, we identified twenty-five studies meeting our inclusion criteria. Considering only nineteen higher-quality studies, our meta-analyses suggest a similar risk of ischemic stroke for rivaroxaban versus dabigatran (HR, 0.93; 95\% CI, 0.83 to 1.04 ), apixaban versus dabigatran (HR, $0.94 ; 95 \% \mathrm{CI}, 0.82$ to 1.09 ), and apixaban versus rivaroxaban (HR, 1.07; 95\% CI, 0.93 to 1.23). Moreover, we observed an increased risk of major bleeding for rivaroxaban versus dabigatran (HR, 1.33; 95\% CI, 1.20 to 1.47$)$ and decreased risks for apixaban versus either dabigatran (HR, $0.71 ; 95 \% \mathrm{CI}, 0.64$ to 0.78$)$ or rivaroxaban $(\mathrm{HR}, 0.56$; 95\% CI, 0.48 to 0.65$)$.

Some studies included in this systematic review had several limitations that warrant consideration. Using the ROBINS-I tool, we found that nineteen studies were assigned a moderate risk of bias, $[11,12,16-27,34,37,38,40,41]$ while six studies were assigned a serious or critical risk of bias.[13-15, 35, 36, 39] A potential limitation observed in all studies with a serious or critical risk of bias was confounding by indication, contraindication, and/or severity related to previous use of VKAs. The remaining studies considered previous VKA use in their design, either by matching on propensity scores that included previous VKA use as a variable or by excluding previous VKA users. While the first approach does not eliminate the possibility of residual confounding since aspects such as duration of previous VKA use are not taken into consideration, the second approach may yield findings of decreased generalizability as many DOAC users are previous VKA users.[43] The prevalent new-user study design, a newly-developed approach incorporating both new users and switchers from previous medications that considers the duration of previous treatment could offer an alternative in this setting.[44] Another major limitation was 
This is a post-peer-review, pre-copyedit version of an article published in 'Drug Safety'. The final authenticated version is available online at: https://doi.org/10.1007/s40264-019-00842-1. The following terms of use apply: https://www.springer.com/gp/ope

the indiscriminate inclusion of prevalent users, $[15,36]$ which may result in under-ascertainment of early adverse events, depletion of susceptibles, and adjusting for covariates in the causal pathway.[45, 46]

Our findings of a similar risk of ischemic stroke among DOACs as well as the decreased risk of major bleeding with apixaban compared with either rivaroxaban or dabigatran are congruent with those of a recent systematic review of network meta-analyses of randomized controlled trials.[47] Moreover, our findings that rivaroxaban could be associated with an increased risk of major bleeding and all-cause mortality compared with dabigatran are congruent with those of the meta-analysis by Bai et al.[7] However, while Bai et al. reported no differences between rivaroxaban and dabigatran regarding intracranial hemorrhage (HR, 1.22; 95\% CI, 0.85 to 1.59),[7] our pooled estimate suggested a $71 \%$ increased risk for rivaroxaban. A possible explanation for this discrepancy is that Bai et al. also included two studies assigned a serious of bias in our quality assessment that suggested a decreased risk for rivaroxaban.[35, 39]

The higher risks for different types of bleeding observed with rivaroxaban compared with dabigatran or apixaban could be a result of the dosing regimens. Indeed, while DOACs have similar plasma half-lives, [48] rivaroxaban is given once daily as opposed to dabigatran and apixaban that are given twice daily. It is conceivable that once-daily regimens could lead to higher peak levels and to increased risk of bleeding. However, to our knowledge, a correlation between rivaroxaban plasma levels and bleeding events has yet to be shown.

Our study has several strengths. First, it provides an up-to-date synthesis of the available literature in a dynamically evolving field, including several recent studies not captured in previous systematic reviews and considering overall almost half a million DOAC users. Second, this study presents robust data on the comparative effectiveness and safety of apixaban, a relatively recently 
This is a post-peer-review, pre-copyedit version of an article published in 'Drug Safety'. The final authenticated version is available online at: https://doi.org/10.1007/s40264-019-00842-1. The following terms of use apply: https://www.springer.com/gp/ope

approved DOAC. Finally, we used ROBINS-I to evaluate the quality of the included studies, a tool that enables a robust assessment of the risk of different biases such as confounding or selection bias, and restricted meta-analysis to higher quality studies.

Our study also has some limitations. First, our review is affected by the limitations of the included studies such as residual confounding due to clinical data not typically captured by administrative databases (e.g., smoking, diet). Second, while the exclusion of studies with $<1000$ DOAC users provides an objective, pre-specified threshold based on underlying event rates, there is a possibility that some underpowered but potentially eligible studies could have been excluded. Finally, as the included studies were conducted using computerized healthcare databases from different jurisdictions, confounding due to jurisdiction-specific factors such as formulary restrictions cannot be excluded.

\section{CONCLUSIONS}

Our systematic review and meta-analysis suggest no major differences in the risk of ischemic stroke, all-cause mortality, myocardial infarction, or systemic embolism between dabigatran, rivaroxaban, and apixaban in patients with AF. However, rivaroxaban is associated with an increased risk of bleeding compared with dabigatran, while apixaban is associated with a decreased risk of bleeding compared with either dabigatran or rivaroxaban. Thus, current observational evidence supports the notion that while differences among DOACs regarding effectiveness appear to be small, apixaban should be preferred in AF patients at higher risk of bleeding. 
This is a post-peer-review, pre-copyedit version of an article published in 'Drug Safety'. The final authenticated version is available online at: https://doi.org/10.1007/s40264-019-00842-1. The following terms of use apply: https://www.springer.com/gp/ope

\section{ACKNOWLEDGEMENTS}

A.D. is the recipient of a Research Fellowship from the German Research Foundation (Deutsche Forschungsgemeinschaft). M.D. holds a Chercheur Boursier Clinicien award from the Fonds de recherche du Québec-Santé (FRQS; Quebec Foundation for Health Research). K.B.F holds a Chercheur Boursier award from the FRQS and a William Dawson Scholar award from McGill University.

\section{COMPLIANCE WITH ETHICAL STANDARDS}

Conflict of interest: Antonios Douros, Madeleine Durand, Carla M. Doyle, Sarah Yoon, Pauline Reynier, and Kristian B. Filion have no conflicts of interest that are directly relevant to the content of this study.

Funding: This research was funded by the Canadian Network for Observational Drug Effects Studies (CNODES), a collaborating center of the Drug Safety and Effectiveness Network (DSEN), funded by the Canadian Institutes of Health Research (Grant Number DSE-146021). *The CNODES Investigators are: Samy Suissa (Principal Investigator); Colin R. Dormuth (British Columbia); Brenda R. Hemmelgarn (Alberta); Gary F. Teare (Saskatchewan); Patricia Caetano and Dan Chateau (Manitoba); David A. Henry and J. Michael Paterson (Ontario); Jacques LeLorier (Québec); Adrian R. Levy (Atlantic [Nova Scotia, Newfoundland and Labrador, New Brunswick,

Prince Edward Island]); Pierre Ernst and Kristian B. Filion (United Kingdom Clinical Practice Research Datalink [CPRD]); Robert W. Platt (Methods); and Ingrid S. Sketris (Knowledge Translation).

Ethical approval: Not applicable

Patient consent: Not applicable 
This is a post-peer-review, pre-copyedit version of an article published in 'Drug Safety'. The final authenticated version is available online at: https://doi.org/10.1007/s40264-019-00842-1. The following terms of use apply: https://www.springer.com/gp/ope

\section{CONTRIBUTIONS OF AUTHORS}

A.D. contributed to the study conception, assessed the quality of the studies, and drafted the manuscript. M.D. provided clinical expertise to several of the criteria used in bias assessment and reviewed the manuscript for important intellectual content. C.M.D. contributed to the study conception, performed the search and the data extraction, and reviewed the manuscript for important intellectual content. S.Y. contributed to the study conception, performed the search and the data extraction, assessed the quality of the studies, and reviewed the manuscript for important intellectual content. P.R. conducted the statistical analyses and reviewed the manuscript for important intellectual content. K.B.F. supervised the project, contributed to study conception, and reviewed the manuscript for important intellectual content. 
This is a post-peer-review, pre-copyedit version of an article published in 'Drug Safety'. The final authenticated version is available online at: https://doi.org/10.1007/s40264-019-00842-1. The following terms of use apply: https://www.springer.com/gp/ope

\section{REFERENCES}

1. Wolf PA, Abbott RD, Kannel WB. Atrial fibrillation as an independent risk factor for stroke: the Framingham Study. Stroke. 1991 Aug;22(8):983-8.

2. Ufer M. Comparative pharmacokinetics of vitamin $\mathrm{K}$ antagonists: warfarin, phenprocoumon and acenocoumarol. Clin Pharmacokinet. 2005;44(12):1227-46.

3. Ruff CT, Giugliano RP, Braunwald E, Hoffman EB, Deenadayalu N, Ezekowitz MD, et al. Comparison of the efficacy and safety of new oral anticoagulants with warfarin in patients with atrial fibrillation: a meta-analysis of randomised trials. Lancet. 2014 Mar 15;383(9921):955-62.

4. January CT, Wann LS, Alpert JS, Calkins H, Cigarroa JE, Cleveland JC, Jr., et al. 2014 AHA/ACC/HRS guideline for the management of patients with atrial fibrillation. Circulation. 2014 Dec 2;130(23):e199-267.

5. Kirchhof P, Benussi S, Kotecha D, Ahlsson A, Atar D, Casadei B, et al. 2016 ESC Guidelines for the management of atrial fibrillation developed in collaboration with EACTS. Eur Heart J. 2016 Aug 27.

6. Meschia JF, Bushnell C, Boden-Albala B, Braun LT, Bravata DM, Chaturvedi S, et al. Guidelines for the primary prevention of stroke: a statement for healthcare professionals from the American Heart Association/American Stroke Association. Stroke. 2014 Dec;45(12):3754-832.

7. Bai Y, Deng H, Shantsila A, Lip GY. Rivaroxaban Versus Dabigatran or Warfarin in RealWorld Studies of Stroke Prevention in Atrial Fibrillation: Systematic Review and Meta-Analysis. Stroke. 2017 Apr;48(4):970-6.

8. Bundhun PK, Soogund MZ, Teeluck AR, Pursun M, Bhurtu A, Huang WQ. Bleeding outcomes associated with rivaroxaban and dabigatran in patients treated for atrial fibrillation: a systematic review and meta-analysis. BMC Cardiovasc Dis. 2017 Jan 6;17(1):15. 
This is a post-peer-review, pre-copyedit version of an article published in 'Drug Safety'. The final authenticated version is available online at: https://doi.org/10.1007/s40264-019-00842-1. The following terms of use apply: https://www.springer.com/gp/ope

9. Bai Y, Shi XB, Ma CS, Lip GYH. Meta-Analysis of Effectiveness and Safety of Oral Anticoagulants in Atrial Fibrillation With Focus on Apixaban. Am J Cardiol. 2017 Nov 1;120(9):1689-95.

10. Deitelzweig S, Farmer C, Luo X, Vo L, Li X, Hamilton M, et al. Risk of major bleeding in patients with non-valvular atrial fibrillation treated with oral anticoagulants: a systematic review of real-world observational studies. Curr Med Res Opin. 2017 Sep;33(9):1583-94.

11. Abraham NS, Noseworthy PA, Yao X, Sangaralingham LR, Shah ND. Gastrointestinal Safety of Direct Oral Anticoagulants: A Large Population-Based Study. Gastroenterology. 2017 Apr;152(5):1014-22.e1.

12. Hernandez I, Zhang Y, Saba S. Comparison of the Effectiveness and Safety of Apixaban, Dabigatran, Rivaroxaban, and Warfarin in Newly Diagnosed Atrial Fibrillation. Am J Cardiol. 2017 Nov 15;120(10):1813-9.

13. Lai CL, Chen HM, Liao MT, Lin TT, Chan KA. Comparative Effectiveness and Safety of Dabigatran and Rivaroxaban in Atrial Fibrillation Patients. J Am Heart Assoc. 2017 Apr 24;6(4). 14. Lamberts M, Staerk L, Olesen JB, Fosbol EL, Hansen ML, Harboe L, et al. Major Bleeding Complications and Persistence With Oral Anticoagulation in Non-Valvular Atrial Fibrillation: Contemporary Findings in Real-Life Danish Patients. J Am Heart Assoc. 2017 Feb 14;6(2). 15. Li WH, Huang D, Chiang CE, Lau CP, Tse HF, Chan EW, et al. Efficacy and safety of dabigatran, rivaroxaban, and warfarin for stroke prevention in Chinese patients with atrial fibrillation: the Hong Kong Atrial Fibrillation Project. Clin Cardiol. 2017 Apr;40(4):222-9. 16. Lin J, Trocio J, Gupta K, Mardekian J, Lingohr-Smith M, Menges B, et al. Major bleeding risk and healthcare economic outcomes of non-valvular atrial fibrillation patients newly-initiated with oral anticoagulant therapy in the real-world setting. J Med Econ. 201702 Sep;20(9):952-61. 
This is a post-peer-review, pre-copyedit version of an article published in 'Drug Safety'. The final authenticated version is available online at: https://doi.org/10.1007/s40264-019-00842-1. The following terms of use apply: https://www.springer.com/gp/ope

17. Norby FL, Bengtson LGS, Lutsey PL, Chen LY, MacLehose RF, Chamberlain AM, et al. Comparative effectiveness of rivaroxaban versus warfarin or dabigatran for the treatment of patients with non-valvular atrial fibrillation. BMC Cardiovasc Dis. 2017 Sep 6;17(1):238.

18. Staerk L, Gerds TA, Lip GYH, Ozenne B, Bonde AN, Lamberts M, et al. Standard and reduced doses of dabigatran, rivaroxaban and apixaban for stroke prevention in atrial fibrillation: a nationwide cohort study. J Intern Med. 2018 Jan;283(1):45-55.

19. Amin A, Keshishian A, Trocio J, Dina O, Le H, Rosenblatt L, et al. A Real-World Observational Study of Hospitalization and Health Care Costs Among Nonvalvular Atrial Fibrillation Patients Prescribed Oral Anticoagulants in the U.S. Medicare Population. J Manag Care Pharm. 2018 Sep;24(9):911-20.

20. Amin A, Keshishian A, Vo L, Zhang Q, Dina O, Patel C, et al. Real-world comparison of all-cause hospitalizations, hospitalizations due to stroke and major bleeding, and costs for nonvalvular atrial fibrillation patients prescribed oral anticoagulants in a US health plan. J Med Econ. 2018 Mar;21(3):244-53.

21. Andersson NW, Svanstrom H, Lund M, Pasternak B, Melbye M. Comparative effectiveness and safety of apixaban, dabigatran, and rivaroxaban in patients with non-valvular atrial fibrillation. Int J Cardiol. 2018 Oct 1;268:113-9.

22. Blin P, Dureau-Pournin C, Cottin Y, Benichou J, Mismetti P, Abouelfath A, et al. Comparative Effectiveness and Safety of Standard or Reduced Dose Dabigatran vs. Rivaroxaban in Nonvalvular Atrial Fibrillation. Clin Pharmacol Ther. 2019.

23. Graham DJ, Baro E, Zhang R, Liao J, Wernecke M, Reichman ME, et al. Comparative Stroke, Bleeding, and Mortality Risks in Older Medicare Patients Treated with Oral Anticoagulants for Nonvalvular Atrial Fibrillation. Am J Med. 2019. 
This is a post-peer-review, pre-copyedit version of an article published in 'Drug Safety'. The final authenticated version is available online at: https://doi.org/10.1007/s40264-019-00842-1. The following terms of use apply: https://www.springer.com/gp/ope

24. Gupta K, Trocio J, Keshishian A, Zhang Q, Dina O, Mardekian J, et al. Real-World Comparative Effectiveness, Safety, and Health Care Costs of Oral Anticoagulants in Nonvalvular Atrial Fibrillation Patients in the U.S. Department of Defense Population. J Manag Care Pharm. 2018 Nov;24(11):1116-27.

25. Lip GYH, Keshishian A, Li X, Hamilton M, Masseria C, Gupta K, et al. Effectiveness and Safety of Oral Anticoagulants Among Nonvalvular Atrial Fibrillation Patients. Stroke. 201801 Dec;49(12):2933-44.

26. Villines TC, Ahmad A, Petrini M, Tang W, Evans A, Rush T, et al. Comparative safety and effectiveness of dabigatran vs. rivaroxaban and apixaban in patients with non-valvular atrial fibrillation: a retrospective study from a large healthcare system. Eur Heart J Cardiovasc Pharmacother. 2019 Apr 1;5(2):80-90.

27. Vinogradova Y, Coupland C, Hill T, Hippisley-Cox J. Risks and benefits of direct oral anticoagulants versus warfarin in a real world setting: cohort study in primary care. BMJ. 2018 $04 \mathrm{Jul} ; 362: \mathrm{k} 2505$.

28. Moher D, Liberati A, Tetzlaff J, Altman DG. Preferred reporting items for systematic reviews and meta-analyses: the PRISMA statement. BMJ. 2009 Jul 21;339:b2535.

29. Stroup DF, Berlin JA, Morton SC, Olkin I, Williamson GD, Rennie D, et al. Meta-analysis of observational studies in epidemiology: a proposal for reporting. Meta-analysis Of Observational Studies in Epidemiology (MOOSE) group. JAMA. 2000 Apr 19;283(15):2008-12. 30. Gage BF, Waterman AD, Shannon W, Boechler M, Rich MW, Radford MJ. Validation of clinical classification schemes for predicting stroke: results from the National Registry of Atrial Fibrillation. JAMA. 2001 Jun 13;285(22):2864-70. 
This is a post-peer-review, pre-copyedit version of an article published in 'Drug Safety'. The final authenticated version is available online at: https://doi.org/10.1007/s40264-019-00842-1. The following terms of use apply: https://www.springer.com/gp/ope

31. Lip GY, Nieuwlaat R, Pisters R, Lane DA, Crijns HJ. Refining clinical risk stratification for predicting stroke and thromboembolism in atrial fibrillation using a novel risk factor-based approach: the euro heart survey on atrial fibrillation. Chest. 2010 Feb;137(2):263-72.

32. Pisters R, Lane DA, Nieuwlaat R, de Vos CB, Crijns HJ, Lip GY. A novel user-friendly score (HAS-BLED) to assess 1-year risk of major bleeding in patients with atrial fibrillation: the Euro Heart Survey. Chest. 2010 Nov;138(5):1093-100.

33. Jüni P, Loke Y, Pigott T, Ramsay C, Regidor D, Rothstein H, et al. Risk Of Bias In Nonrandomized Studies of Interventions (ROBINS-I): Detailed Guidance. 2016.

34. Adeboyeje G, Sylwestrzak G, Barron JJ, White J, Rosenberg A, Abarca J, et al. Major bleeding risk during anticoagulation with warfarin, dabigatran, apixaban, or rivaroxaban in patients with nonvalvular atrial fibrillation. J Manag Care Pharm. 201701 Sep;23(9):968-78. 35. Chan YH, Kuo CT, Yeh YH, Chang SH, Wu LS, Lee HF, et al. Thromboembolic, Bleeding, and Mortality Risks of Rivaroxaban and Dabigatran in Asians With Nonvalvular Atrial Fibrillation. J Am Coll Cardiol. 2016 Sep 27;68(13):1389-401.

36. Deitelzweig S, Bruno A, Trocio J, Tate N, Gupta K, Lin J, et al. An early evaluation of bleeding-related hospital readmissions among hospitalized patients with nonvalvular atrial fibrillation treated with direct oral anticoagulants. Curr Med Res Opin. 2016;32(3):573-82. 37. Gorst-Rasmussen A, Lip GY, Bjerregaard Larsen T. Rivaroxaban versus warfarin and dabigatran in atrial fibrillation: comparative effectiveness and safety in Danish routine care. Pharmacoepidemiol Drug Saf. 2016 Nov;25(11):1236-44.

38. Graham DJ, Reichman ME, Wernecke M, Hsueh YH, Izem R, Southworth MR, et al. Stroke, Bleeding, and Mortality Risks in Elderly Medicare Beneficiaries Treated With 
This is a post-peer-review, pre-copyedit version of an article published in 'Drug Safety'. The final authenticated version is available online at: https://doi.org/10.1007/s40264-019-00842-1. The following terms of use apply: https://www.springer.com/gp/ope

Dabigatran or Rivaroxaban for Nonvalvular Atrial Fibrillation. JAMA Intern Med. 2016 Nov $1 ; 176(11): 1662-71$.

39. Hernandez I, Zhang Y. Comparing Stroke and Bleeding with Rivaroxaban and Dabigatran in Atrial Fibrillation: Analysis of the US Medicare Part D Data. Am J Cardiovasc Drugs. 2017 Feb;17(1):37-47.

40. Lip GY, Keshishian A, Kamble S, Pan X, Mardekian J, Horblyuk R, et al. Real-world comparison of major bleeding risk among non-valvular atrial fibrillation patients initiated on apixaban, dabigatran, rivaroxaban, or warfarin. A propensity score matched analysis. Thromb Haemost. 2016 Oct 28;116(5):975-86.

41. Noseworthy PA, Yao X, Abraham NS, Sangaralingham LR, McBane RD, Shah ND. Direct Comparison of Dabigatran, Rivaroxaban, and Apixaban for Effectiveness and Safety in Nonvalvular Atrial Fibrillation. Chest. 2016 Dec;150(6):1302-12.

42. Rosenbaum PR, Rubin DB. The central role of the propensity score in observational studies for causal effects. Biometrika. 1983;70(1):41-55.

43. Douros A, Renoux C, Coulombe J, Suissa S. Patterns of long-term use of non-vitamin K antagonist oral anticoagulants for non-valvular atrial fibrillation: Quebec observational study. Pharmacoepidemiol Drug Saf. 2017 Dec;26(12):1546-54.

44. Suissa S, Moodie EE, Dell'Aniello S. Prevalent new-user cohort designs for comparative drug effect studies by time-conditional propensity scores. Pharmacoepidemiol Drug Saf. 2017 Apr;26(4):459-68.

45. Ray WA. Evaluating medication effects outside of clinical trials: new-user designs. Am J Epidemiol. 2003 Nov 01;158(9):915-20. 
This is a post-peer-review, pre-copyedit version of an article published in 'Drug Safety'. The final authenticated version is available online at: https://doi.org/10.1007/s40264-019-00842-1. The following terms of use apply: https://www.springer.com/gp/ope

46. Schisterman EF, Cole SR, Platt RW. Overadjustment Bias and Unnecessary Adjustment in Epidemiologic Studies. Epidemiology. 2009;20(4):488-95.

47. Cohen AT, Hill NR, Luo X, Masseria C, Abariga SA, Ashaye AO. A systematic review of network meta-analyses among patients with nonvalvular atrial fibrillation: A comparison of efficacy and safety following treatment with direct oral anticoagulants. Int J Cardiol. 2018 Oct $15 ; 269: 174-81$.

48. Ageno W, Beyer-Westendorf J, Rubboli A. Once- versus twice-daily direct oral anticoagulants in non-valvular atrial fibrillation. Exp Opin Pharmacother. 2017 2017/09/02;18(13):1325-32. 
This is a post-peer-review, pre-copyedit version of an article published in 'Drug Safety'. The final authenticated version is available online at: https://doi.org/10.1007/s40264-019-00842-1. The following terms of use apply: https://www.springer.com/gp/ope

\section{FIGURE LEGENDS}

Figure 1. Forest plot demonstrating individual and pooled relative risks of ischemic stroke for the comparison rivaroxaban versus dabigatran in patients with atrial fibrillation Abbreviations: HR, hazard ratio; CI, confidence interval.

Figure 2. Forest plots demonstrating individual and pooled relative risks of major bleeding for head-to-head comparisons among different DOACs in patients with atrial fibrillation Abbreviations: DOACs, direct oral anticoagulants; HR, hazard ratio; CI, confidence interval. 
This is a post-peer-review, pre-copyedit version of an article published in 'Drug Safety'. The final authenticated version is available online at: https://doi.org/10.1007/s40264-019-00842-1. The following terms of use apply: https://www.springer.com/gp/ope

Table 1. Characteristics of observational studies on effectiveness and safety of DOACs among patients with AF

\begin{tabular}{|c|c|c|c|c|c|c|c|c|}
\hline Study & Country & Data source & Study population & $\begin{array}{l}\text { Study } \\
\text { period }\end{array}$ & DOACs* & $\begin{array}{l}\text { Patients } \\
\text { (n) } * *\end{array}$ & $\begin{array}{c}\text { Follow-up } \\
(\mathbf{d}) * * * *\end{array}$ & Outcomes \\
\hline \multirow{3}{*}{$\begin{array}{l}\text { Abraham } \\
\text { et al.[11] }\end{array}$} & \multirow{3}{*}{ USA } & \multirow{3}{*}{ Optum } & \multirow{3}{*}{$\begin{array}{l}\text { NVAF patients initiating } \\
\text { DABI, RIVA or APIXA }\end{array}$} & \multirow{3}{*}{ 2010-2015 } & RIVA vs DABI & $15,787 / 15,787$ & $113 / 120$ & \multirow{3}{*}{ GIB } \\
\hline & & & & & APIXA vs DABI & $6542 / 6542$ & $89 / 120$ & \\
\hline & & & & & APIXA vs RIVA & $6565 / 6565$ & $89 / 106$ & \\
\hline \multirow{3}{*}{$\begin{array}{l}\text { Adeboyeje } \\
\text { et al.[34] }\end{array}$} & \multirow{3}{*}{ USA } & \multirow{3}{*}{$\begin{array}{l}\text { HealthCore Integrated } \\
\text { Research Environment }\end{array}$} & \multirow{3}{*}{$\begin{array}{l}\text { NVAF patients initiating } \\
\text { oral anticoagulation with } \\
\text { DABI, RIVA, or APIXA }\end{array}$} & \multirow{3}{*}{ 2009-2016 } & RIVA vs DABI ${ }^{\S \S \S}$ & $8398 / 8539$ & $169 / 212$ & \multirow{3}{*}{$\mathrm{MB}, \mathrm{GIB}, \mathrm{ICH}$} \\
\hline & & & & & APIXA vs DABI & $3689 / 8539$ & $139 / 212$ & \\
\hline & & & & & APIXA vs RIVA & $3689 / 8398$ & $139 / 169$ & \\
\hline \multirow{2}{*}{$\begin{array}{l}\text { Amin } \\
\text { et al.[19] }\end{array}$} & \multirow{2}{*}{ USA } & \multirow{2}{*}{ Medicare } & \multirow{2}{*}{$\begin{array}{l}\text { NVAF patients initiating } \\
\text { oral anticoagulation with } \\
\text { DABI, RIVA, or APIXA }\end{array}$} & \multirow{2}{*}{ 2013-2014 } & APIXA vs DABI ${ }^{\S}$ & $15,418 / 15,418$ & $115 / 113$ & \multirow{2}{*}{$\begin{array}{l}\text { Ischemic stroke, major bleeding, } \\
\text { SE, ICH, hemorrhagic stroke, GIB }\end{array}$} \\
\hline & & & & & APIXA vs RIVA ${ }^{\S \S}$ & $20,804 / 20,804$ & $115 / 133$ & \\
\hline \multirow{2}{*}{$\begin{array}{l}\text { Amin } \\
\text { et al.[20] }\end{array}$} & \multirow{2}{*}{ USA } & \multirow{2}{*}{ Optum } & \multirow{2}{*}{$\begin{array}{l}\text { NVAF patients initiating } \\
\text { oral anticoagulation with } \\
\text { DABI, RIVA, or APIXA }\end{array}$} & \multirow{2}{*}{$2013-2015$} & APIXA vs DABI ${ }^{\S}$ & $3557 / 3557$ & NI & \multirow{2}{*}{ Major bleeding } \\
\hline & & & & & APIXA vs RIVA ${ }^{\S \S}$ & $8440 / 8440$ & NI & \\
\hline \multirow{3}{*}{$\begin{array}{l}\text { Andersson } \\
\text { et al.[21] }\end{array}$} & \multirow{3}{*}{ Denmark } & \multirow{3}{*}{$\begin{array}{c}\text { Danish nation-wide } \\
\text { administrative registries }\end{array}$} & \multirow{3}{*}{$\begin{array}{l}\text { NVAF patients initiating } \\
\text { oral anticoagulation with } \\
\text { DABI, RIVA, or APIXA }\end{array}$} & \multirow{3}{*}{$2013-2016$} & $\begin{array}{l}\text { RIVA 20mg vs } \\
\text { DABI } 150 \mathrm{mg}\end{array}$ & $2720 / 2720$ & $204 / 243$ & \multirow{3}{*}{$\begin{array}{l}\text { Ischemic stroke, major bleeding, } \\
\text { SE, ICH, hemorrhagic stroke, GIB }\end{array}$} \\
\hline & & & & & $\begin{array}{l}\text { APIXA } 5 \mathrm{mg} \text { vs } \\
\text { DABI } 150 \mathrm{mg}\end{array}$ & $3235 / 3235$ & $210 / 241$ & \\
\hline & & & & & $\begin{array}{l}\text { APIXA 5mg vs } \\
\text { RIVA 20mg }\end{array}$ & $3676 / 3676$ & $212 / 201$ & \\
\hline $\begin{array}{l}\text { Blin } \\
\text { et al.[22] }\end{array}$ & France & $\begin{array}{c}\text { French Healthcare } \\
\text { Database }\end{array}$ & $\begin{array}{l}\text { NVAF patients initiating } \\
\text { oral anticoagulation with } \\
\text { DABI or RIVA }\end{array}$ & 2013-2014 & $\begin{array}{l}\text { RIVA } 20 \mathrm{mg} \text { vs } \\
\text { DABI } 150 \mathrm{mg} \S \S\end{array}$ & $8290 / 8290$ & NI & $\begin{array}{l}\text { Ischemic stroke, major bleeding, } \\
\text { all-cause mortality, SE, MI, ICH, } \\
\text { GIB, clinically relevant bleeding, } \\
\text { urogenital bleeding }\end{array}$ \\
\hline $\begin{array}{l}\text { Chan } \\
\text { et al.[35] }\end{array}$ & Taiwan & $\begin{array}{l}\text { Taiwan National Health } \\
\text { Insurance Research } \\
\text { Database }\end{array}$ & $\begin{array}{l}\text { NVAF patients initiating } \\
\text { DABI or RIVA }\end{array}$ & 2013 & RIVA vs DABI & $3916 / 5921$ & NI & $\begin{array}{l}\text { Ischemic stroke, major bleeding, } \\
\text { all-cause mortality, MI, ICH, GIB }\end{array}$ \\
\hline \multirow{4}{*}{$\begin{array}{l}\text { Deitelzweig } \\
\text { et al.[36] }\end{array}$} & \multirow{4}{*}{ USA } & \multirow{4}{*}{$\begin{array}{l}\text { Premier Hospital } \\
\text { database }\end{array}$} & \multirow{4}{*}{$\begin{array}{l}\text { NVAF patients treated } \\
\text { with DABI, RIVA or } \\
\text { APIXA }\end{array}$} & \multirow{4}{*}{$2012-2014$} & APIXA vs DABI ${ }^{\S}$ & $4138 / 32,838$ & & \\
\hline & & & & & APIXA vs RIVA ${ }^{\S \S}$ & $4138 / 37,754$ & NI & Maior bleedino \\
\hline & & & & & APIXA vs DABI ${ }^{\S}$ & $1813 / 5753$ & & \\
\hline & & & & & APIXA vs RIVA ${ }^{\S \S}$ & $1813 / 6635$ & & \\
\hline
\end{tabular}


This is a post-peer-review, pre-copyedit version of an article published in 'Drug Safety'. The final authenticated version is available online at: https://doi.org/10.1007/s40264-019-00842-1. The following terms of use apply: https://www.springer.com/gp/ope

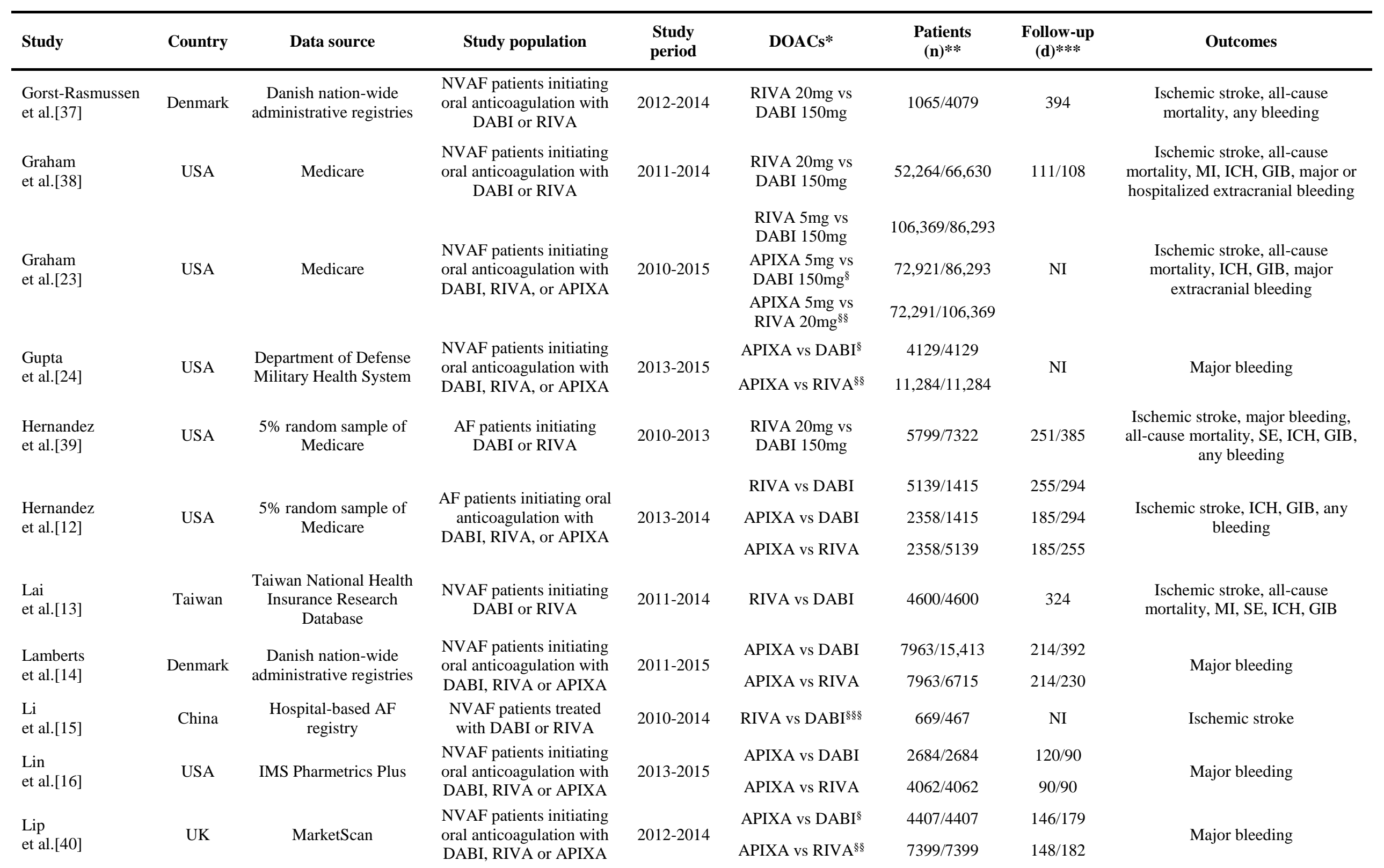


This is a post-peer-review, pre-copyedit version of an article published in 'Drug Safety'. The final authenticated version is available online at: https://doi.org/10.1007/s40264-019-00842-1. The following terms of use apply: https://www.springer.com/gp/ope

\begin{tabular}{|c|c|c|c|c|c|c|c|c|}
\hline Study & Country & Data source & Study population & $\begin{array}{l}\text { Study } \\
\text { period }\end{array}$ & DOACs* & $\begin{array}{c}\text { Patients } \\
(\mathbf{n})^{* *}\end{array}$ & $\begin{array}{c}\text { Follow-up } \\
(\text { d) } * * *\end{array}$ & Outcomes \\
\hline \multirow{4}{*}{$\begin{array}{l}\text { Lip } \\
\text { et al.[25] }\end{array}$} & \multirow{4}{*}{ USA } & \multirow{4}{*}{$\begin{array}{l}\text { Medicare, MarketScan, } \\
\text { IMS PharMetrics Plus, } \\
\text { Optum, Humana } \\
\text { Research Database }\end{array}$} & \multirow{4}{*}{$\begin{array}{l}\text { NVAF patients initiating } \\
\text { oral anticoagulation with } \\
\text { DABI, RIVA, or APIXA }\end{array}$} & \multirow{4}{*}{ 2013-2015 } & RIVA vs DABI & $4657 / 4657$ & $173 / 177$ & \multirow{4}{*}{$\begin{array}{l}\text { Ischemic stroke, major bleeding, } \\
\text { SE, ICH, hemorrhagic stroke, GIB }\end{array}$} \\
\hline & & & & & RIVA vs DABI ${ }^{\S \S \S}$ & $27,538 / 27,538$ & $149 / 128$ & \\
\hline & & & & & APIXA vs DABI & $27,096 / 27,096$ & $133 / 130$ & \\
\hline & & & & & APIXA vs RIVA & $62,619 / 62 / 619$ & $133 / 149$ & \\
\hline $\begin{array}{l}\text { Norby } \\
\text { et al.[17] }\end{array}$ & USA & MarketScan & $\begin{array}{l}\text { NVAF patients initiating } \\
\text { oral anticoagulation with } \\
\text { DABI or RIVA }\end{array}$ & 2010-2014 & RIVA vs DABI & $16,957 / 16,957$ & NI & Ischemic stroke, MI, ICH, GIB \\
\hline \multirow{3}{*}{$\begin{array}{l}\text { Noseworthy } \\
\text { et al.[41] }\end{array}$} & \multirow{3}{*}{ USA } & \multirow{3}{*}{ Optum } & \multirow{3}{*}{$\begin{array}{l}\text { NVAF patients initiating } \\
\text { DABI, RIVA or APIXA }\end{array}$} & \multirow{3}{*}{ 2010-2015 } & RIVA vs DABI & $15,787 / 15,787$ & & \multirow{3}{*}{$\begin{array}{l}\text { Ischemic stroke, major bleeding, } \\
\text { ICH, hemorrhagic stroke }\end{array}$} \\
\hline & & & & & APIXA vs DABI & $6542 / 6542$ & NI & \\
\hline & & & & & APIXA vs RIVA & $6565 / 6565$ & & \\
\hline \multirow{3}{*}{$\begin{array}{l}\text { Staerk } \\
\text { et al.[18] }\end{array}$} & \multirow{3}{*}{ Denmark } & \multirow{3}{*}{$\begin{array}{c}\text { Danish nation-wide } \\
\text { administrative registries }\end{array}$} & \multirow{3}{*}{$\begin{array}{l}\text { NVAF patients initiating } \\
\text { oral anticoagulation with } \\
\text { DABI, RIVA or APIXA }\end{array}$} & \multirow{3}{*}{ 2012-2016 } & $\begin{array}{l}\text { RIVA } 20 \mathrm{mg} \text { vs } \\
\text { DABI } 150 \mathrm{mg}\end{array}$ & $6868 / 7078$ & & \multirow{3}{*}{$\begin{array}{l}\text { Ischemic stroke, major bleeding, } \\
\text { ICH, GIB }\end{array}$} \\
\hline & & & & & $\begin{array}{l}\text { APIXA 5mg vs } \\
\text { DABI } 150 \mathrm{mg}\end{array}$ & $7203 / 7078$ & NI & \\
\hline & & & & & $\begin{array}{l}\text { APIXA 5mg vs } \\
\text { RIVA 20mg }\end{array}$ & $7203 / 6868$ & & \\
\hline $\begin{array}{l}\text { Villines } \\
\text { et al.[26] }\end{array}$ & USA & $\begin{array}{l}\text { Department of Defense } \\
\text { Military Health System }\end{array}$ & $\begin{array}{l}\text { NVAF patients initiating } \\
\text { oral anticoagulation with } \\
\text { DABI, RIVA, or APIXA }\end{array}$ & 2011-2016 & $\begin{array}{l}\text { RIVA vs DABI }{ }^{\S \S} \\
\text { APIXA vs DABI }^{\S}\end{array}$ & $\begin{array}{c}12,763 / 12,763 \\
4802 / 4802\end{array}$ & $\begin{array}{l}417 / 422 \\
358 / 350\end{array}$ & $\begin{array}{l}\text { Ischemic stroke, major bleeding, } \\
\text { all-cause mortality, MI, ICH, } \\
\text { hemorrhagic stroke, GIB, major } \\
\text { extracranial bleeding }\end{array}$ \\
\hline \multirow{6}{*}{$\begin{array}{l}\text { Vinogradova } \\
\text { et al.[27] }\end{array}$} & \multirow{6}{*}{ UK } & \multirow{4}{*}{ QResearch } & & \multirow{6}{*}{ 2011-2016 } & DABI & 4534 & 271 & \multirow{6}{*}{$\begin{array}{c}\text { Ischemic stroke, major bleeding, } \\
\text { all-cause mortality, ICH, GIB, } \\
\text { urogenital bleeding }\end{array}$} \\
\hline & & & & & RIVA & 13,597 & 265 & \\
\hline & & & AF patients initiating oral & & APIXA & 9199 & 248 & \\
\hline & & & DABI, RIVA, or APIXA & & DABI & 1003 & 214 & \\
\hline & & \multirow[t]{2}{*}{ CPRD } & & & RIVA & 2950 & 163 & \\
\hline & & & & & APIXA & 1402 & 143 & \\
\hline
\end{tabular}

Abbreviations: DOACs, direct oral anticoagulants; AF, atrial fibrillation; NVAF, non-valvular atrial fibrillation; DABI, dabigatran; RIVA, rivaroxaban; APIXA, apixaban; GIB, gastrointestinal bleeding; SE, systemic embolism; MI, myocardial infarction; TIA, transient ischemic attack; ICH, intracranial hemorrhage; NI, no information. 
This is a post-peer-review, pre-copyedit version of an article published in 'Drug Safety'. The final authenticated version is available online at: https://doi.org/10.1007/s40264-019-00842-1. The following terms of use apply: https://www.springer.com/gp/ope

* Comparisons between low-dose regimes (e.g., DABI 110mg or 75mg, RIVA 15mg, or APIXA 2.5mg) are not shown. Comparisons between standard-dose regimes (e.g., DABI 150mg, RIVA 20mg, or APIXA 5mg) are also not shown in case the main analysis was independent of dose.

** Numbers refer to the populations used in the analyses (e.g., post propensity score matching, trimming, or weighting) except for Hernandez et al.[39] that reported numbers only prior to propensity score weighting.

*** Reported as means or medians.

$\S$ The article originally reported estimates for the comparison DABI versus APIXA.

$\S \S$ The article originally reported estimates for the comparison RIVA versus APIXA.

$\S \S$ The article originally reported estimates for the comparison DABI versus RIVA. 
This is a post-peer-review, pre-copyedit version of an article published in 'Drug Safety'. The final authenticated version is available online at: https://doi.org/10.1007/s40264-019-00842-1. The following terms of use apply: https://www.springer.com/gp/ope

Table 2. Results of meta-analyses for the comparative effectiveness and safety of DOACs among patients with AF

\begin{tabular}{|c|c|c|c|c|}
\hline Outcome & Comparison & Studies (n) & Pooled HR (95\% CI) & $\mathbf{I}^{2}(\%)$ \\
\hline \multirow{3}{*}{ Ischemic stroke } & Rivaroxaban vs dabigatran & 6 & $0.93(0.83$ to 1.04$)$ & 0 \\
\hline & Apixaban vs dabigatran & 5 & $0.94(0.82$ to 1.09$)$ & 0 \\
\hline & Apixaban vs rivaroxaban & 4 & $1.07(0.93$ to 1.23$)$ & 0 \\
\hline \multirow{3}{*}{ Major bleeding } & Rivaroxaban vs dabigatran & 6 & 1.33 (1.20 to 1.47$)$ & 22 \\
\hline & Apixaban vs dabigatran & 8 & $0.71(0.64$ to 0.78$)$ & 0 \\
\hline & Apixaban vs rivaroxaban & 8 & $0.56(0.48$ to 0.65$)$ & 69 \\
\hline \multirow{2}{*}{ All-cause mortality } & Rivaroxaban vs dabigatran & 4 & $1.13(1.00$ to 1.28$)$ & 38 \\
\hline & Apixaban vs dabigatran & 3 & $1.00(0.85$ to 1.19$)$ & 60 \\
\hline Myocardial infarction & Rivaroxaban vs dabigatran & 4 & 0.98 (0.86 to 1.12$)$ & 0 \\
\hline Systemic embolism & Rivaroxaban vs dabigatran & 3 & $1.19(0.77$ to 1.82$)$ & 0 \\
\hline \multirow[t]{3}{*}{ Intracranial hemorrhage } & Rivaroxaban vs dabigatran & 7 & $1.71(1.46$ to 2.01$)$ & 0 \\
\hline & Apixaban vs dabigatran & 6 & $1.27(0.98$ to 1.63$)$ & 10 \\
\hline & Apixaban vs rivaroxaban & 5 & $0.80(0.59$ to 1.08$)$ & 37 \\
\hline \multirow[t]{3}{*}{ Hemorrhagic stroke } & Rivaroxaban vs dabigatran & 3 & $2.45(1.23$ to 4.90$)$ & 31 \\
\hline & Apixaban vs dabigatran & 3 & $0.82(0.39$ to 1.72$)$ & 0 \\
\hline & Apixaban vs rivaroxaban & 3 & $0.63(0.23$ to 1.71$)$ & 63 \\
\hline \multirow[t]{3}{*}{ Gastrointestinal bleeding } & Rivaroxaban vs dabigatran & 7 & $1.17(1.02$ to 1.33$)$ & 69 \\
\hline & Apixaban vs dabigatran & 6 & $0.59(0.46$ to 0.75$)$ & 72 \\
\hline & Apixaban vs rivaroxaban & 5 & $0.56(0.36$ to 0.86$)$ & 92 \\
\hline
\end{tabular}

Abbreviations: DOACs, direct oral anticoagulants; AF, atrial fibrillation; HR, hazard ratio; CI, confidence interval 
This is a post-peer-review, pre-copyedit version of an article published in 'Drug Safety'. The final authenticated version is available online at: https://doi.org/10.1007/s40264-019-00842-1. The following terms of use apply: https://www.springer.com/gp/ope

\section{Figure 1}

\section{Study}

Rivaroxaban vs Dabigatran Andersson ${ }^{21}$

Blin $^{22}$

Graham $^{23}$

Norby ${ }^{17}$

Noseworthy ${ }^{41}$

Villines ${ }^{26}$

Random effects model

Heterogeneity: $I^{2}=0 \%, p=0.53$

Apixaban vs Dabigatran

Andersson 21

Graham $^{23}$

Noseworthy ${ }^{41}$

Villines $^{26}$

Vinogradova ${ }^{27}$

Random effects model

Heterogeneity: $I^{2}=0 \%, p=0.74$

Apixaban vs Rivaroxaban Andersson 21

Graham $^{23}$

Noseworthy ${ }^{41}$

Vinogradova ${ }^{27}$

Random effects model

Heterogeneity: $I^{2}=0 \%, p=0.56$

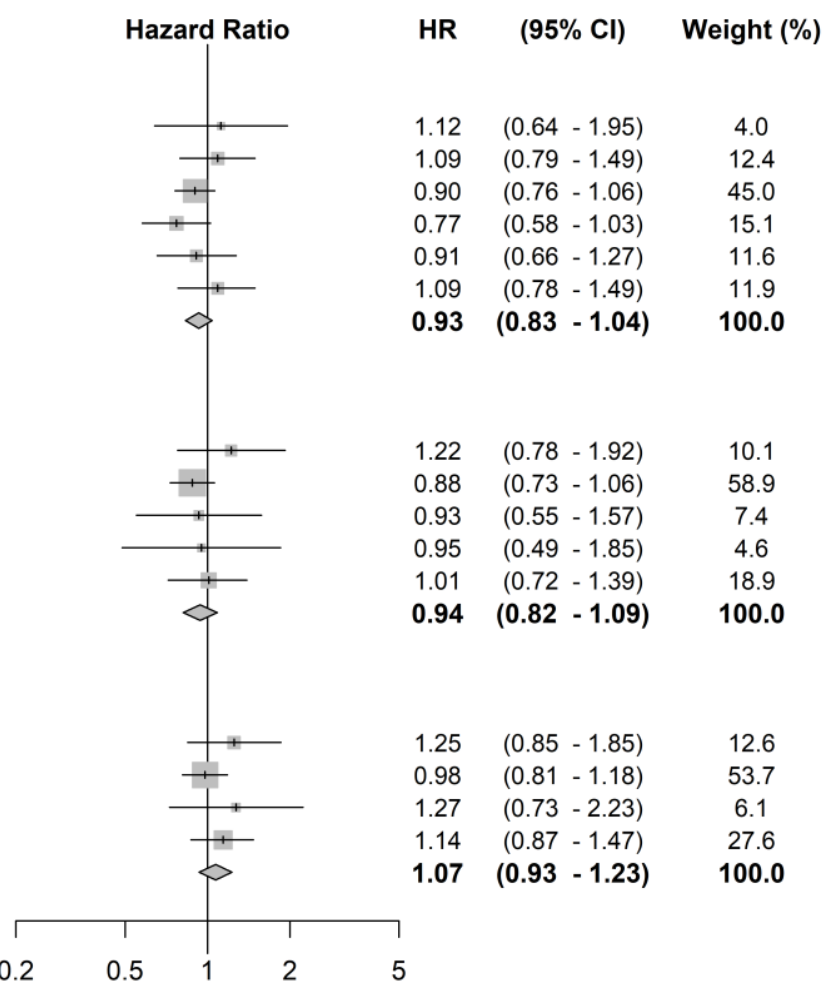


This is a post-peer-review, pre-copyedit version of an article published in 'Drug Safety'. The final authenticated version is available online at: https://doi.org/10.1007/s40264-019-00842-1. The following terms of use apply: https://www.springer.com/gp/ope

Figure 2

\begin{tabular}{|c|c|c|c|c|c|}
\hline Study & Hazarc & d Ratio & HR & $(95 \% \mathrm{Cl})$ & Weight $(\%$ \\
\hline \multicolumn{6}{|l|}{ Rivaroxaban vs Dabigatran } \\
\hline Adeboyeje ${ }^{34}$ & & + & 1.49 & $(1.28-1.72)$ & 18.1 \\
\hline Andersson $^{21}$ & & + & 1.35 & $(0.91-2.00)$ & 15.3 \\
\hline Blin $^{22}$ & & -1 & 1.69 & $(1.11-2.56)$ & 14.9 \\
\hline $\operatorname{Lip}^{40}$ & & 1 & 1.05 & $(0.74-1.49)$ & 15.9 \\
\hline Noseworthy ${ }^{41}$ & & + & 1.30 & $(1.10-1.53)$ & 17.9 \\
\hline Villines ${ }^{26}$ & & + & 1.22 & $(1.03-1.43)$ & 18.0 \\
\hline $\begin{array}{l}\text { Random effects model } \\
\text { Heterogeneity } I^{2}=22 \% \quad D=0.27\end{array}$ & & $\diamond$ & 1.33 & $(1.20-1.47)$ & 100.0 \\
\hline \multicolumn{6}{|l|}{ Apixaban vs Dabigatran } \\
\hline Adeboyeje $^{34}$ & $\longrightarrow$ & & 0.78 & $(0.59-1.01)$ & 13.4 \\
\hline $\operatorname{Amin}^{19}$ & + & & 0.68 & $(0.57-0.80)$ & 14.2 \\
\hline Andersson ${ }^{21}$ & & & 0.94 & $(0.62-1.41)$ & 11.9 \\
\hline $\operatorname{Lin} 16$ & 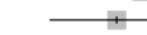 & - & 0.74 & $(0.40-1.30)$ & 9.8 \\
\hline $\operatorname{Lip}^{40}$ & T & & 0.71 & $(0.47-1.08)$ & 11.8 \\
\hline Noseworthy ${ }^{41}$ & 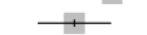 & & 0.50 & $(0.36-0.70)$ & 12.7 \\
\hline Villines ${ }^{26}$ & 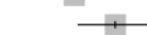 & & 0.73 & $(0.52-1.03)$ & 12.6 \\
\hline Vinogradova ${ }^{27}$ & $\mp$ & & 0.75 & $(0.59-0.97)$ & 13.6 \\
\hline Random effects model & $\diamond$ & & 0.71 & $(0.64-0.78)$ & 100.0 \\
\hline Heterogeneity: $I^{2}=0 \%, p=0.43$ & & & & & \\
\hline \multicolumn{6}{|l|}{ Apixaban vs Rivaroxaban } \\
\hline Adeboyeje $^{34}$ & $\div$ & & 0.52 & $(0.40-0.68)$ & 12.6 \\
\hline $\operatorname{Amin}^{19}$ & & & 0.46 & $(0.40-0.52)$ & 13.6 \\
\hline Andersson $^{21}$ & $\longrightarrow$ & & 0.88 & $(0.64-1.22)$ & 12.1 \\
\hline Gupta $^{24}$ & 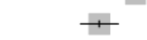 & & 0.63 & $(0.53-0.75)$ & 13.3 \\
\hline $\operatorname{Lin}^{16}$ & 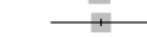 & & 0.64 & $(0.40-1.00)$ & 10.7 \\
\hline $\operatorname{Lip}^{40}$ & 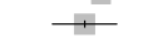 & & 0.55 & $(0.41-0.74)$ & 12.4 \\
\hline Noseworthy ${ }^{41}$ & 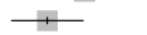 & & 0.39 & $(0.28-0.54)$ & 12.0 \\
\hline Vinogradova 27 & + & & 0.59 & $(0.49-0.71)$ & 13.3 \\
\hline \multirow{2}{*}{$\begin{array}{l}\text { Random effects model } \\
\text { Heterogeneity: } I^{2}=69 \%, p<0.01\end{array}$} & $\infty$ & & 0.56 & $(0.48-0.65)$ & 100.0 \\
\hline & & & & & \\
\hline 0.2 & 0.5 & 2 & 5 & & \\
\hline
\end{tabular}

